\title{
Poverty, user charges and health care demand in Nigeria
}

\author{
Lloyd Ahamefule Amaghionyeodiwe \\ Department of Accounting and Finance \\ York College, City University of New York, New York, USA
}

\section{Key Words}

Poverty, User Charges, Healthcare Demand, Nigeria

\begin{abstract}
Healthcare in Nigeria is paid for on a cash and carry basis while out-of-pocket expenses dominate in households' payment for health care services as a result of user charges that were introduced in the early 1980s. This coupled with the persistent poverty level in Nigeria raises the question of consumers' ability and willingness to pay these user charges. Accordingly, using primary data, this study examined the possible effect of these user charges on the demand for Public Health Care Services in Nigeria, especially how it affects the poor and lowincome earners. The analysis showed that increasing user fees substantially reduced the use of government health facility especially by the poor and the low-income earners. Also, the poor are more likely to trade-off their utilization of public sector health care services for self-treatment or traditional healers, thus significantly lowering their utilization of any modern medical care. Thus, it was recommended, among others, that government should introduce price discrimination into user fees, to be set at marginal cost. This would help avoid the adverse distribution effects of user-fees, especially, on the lower income group.
\end{abstract}

Corresponding author: Lloyd Ahamefule Amaghionyeodiwe

Email address for corresponding author: lamaghionyeodiwe@york.cuny.edu

First submission received: $9^{\text {th }}$ February 2018

Revised submission received: 15 th May 2018

Accepted: $12^{\text {th }}$ June 2018

\subsection{Introduction}

Healthcare in Nigeria is paid for on a cash and carry basis while out-of-pocket expenses dominate in households' payment for health care services. For instance, Ogunbekun et al (1999) indicated that 85 percent of the respondents in their survey sample reported paying for healthcare directly out-of-pocket, this was also supported by estimates from the Federal Ministry of Health (FMoH) (2003) which shows that over 70 percent of healthcare payments in Nigeria are made out-of-pocket. It is worthy to note that prior to this period, (that is, the 1980s) public sector health care services were virtually provided free of charge in Nigeria. With the introduction of user charges, there was an increase in the cost of care being incurred by the consumers and consequently, huge out-of-pocket payments. But given that consumer may have the willingness but not the ability to pay for these services and with huge out-of-pocket payments, there possibly will be a shift or a change in their demand for public health care services.

One vital question in this regard is that of consumers' ability and willingness to pay these user charges, especially given the level of poverty that exists in the Nigerian economy. For instance, according to the World Bank, (1996), the severity of poverty as well as the incidence of extreme poverty increased significantly between 1985 and 1992. While the National Bureau of Statistics (NBS) (2010) reported that the proportion of the core poor increased from 6.2 per cent in 1980 to 29.3 per cent in 1996 and then came down to 21.8 per cent in 2004. The NBS report further shows that the proportion of Nigerians living in poverty is increasing every year as the incidence of poverty increased from $27.2 \%$ in 1980 to $46.3 \%, 42.7 \%, 65.6 \%$, 
$54.4 \%$ and $69.0 \%$ in 1985, 1992, 1996, 2004 and 2010 respectively. This consistent increase in the poverty rate does have an effect on the ability and willingness to pay these charges when consuming health care services in Nigeria.

The ability and willingness to pay (which may not directly covary), therefore determines the quantum and quality of the medical care obtainable by the populace. Households may both have the willingness to pay but the ability to pay will be lacking, especially, in the poor. Yoder (1989) who tried to distinguish between the willingness to pay and the ability to pay maintained that although, they may not directly covary, they are both influenced by some factors of which income and the quality of health care are very important. This was referred to as distributional effect by some studies like Gertler and Van dar Gaag $(1988,1990)$ because the imposition of user charges increases the welfare and medical care utilization of individuals in the top half of the income ladder while reducing those of the individual in the bottom half of the income ladder.

It is as a result of this that the study examines whether the imposition user charges in public sector healthcare facilities can lead to large reductions in the usage of the services of the sector or can cause shifts across types of care used, especially with respect to the low-income earners and the poor. The rest of the paper is structured as follows. Closely following this introductory section is a brief review of the literature which is contained in section two. Section three outlines the methodology and data analysis while the study's findings are discussed in section four. Section five concludes the study.

\section{1: $\quad$ Brief Review of the Literature}

The introduction of user charges as a strategy for easing the health care financing crisis has been questioned, among others, based on its implications for health care utilization. Dor, Gertler and Van der Gaag (1987) and Gertler and Van Der Gaag (1990) showed that the poor are two-to-three times more price responsive than the non-poor in the consumption of medical care. Thus, if prices were significantly raised in the public sector medical facilities, a large proportion of poor households would "migrate" out of this subsector. Their studies were conducted for Cote d'Ivore and Peru respectively. Other studies that support this notion includes Litvack and Bodart (1993) for Cameroon; Lavy and Germain (1994) for Ghana; Ngugi (1999) for Kenya and Amaghionyeodiwe (2007) for Nigeria. These studies found that the introduction of user fees affected health care utilization of the consumers by reducing their use of public health services, particularly for the poor. Deininger and Mpuga (2003) also found user fees to be particularly important in determining access to health services, particularly for the poor,

The conclusions above were confirmed by the studies of Alderman and Gertler (1989) which focused on the substitutability of public and private health care for the treatment of children in Pakistan, and Ching (1995) whose study examined the potential effects of user charges on the demand for children's healthcare across income groups in the Philippines. Moses et al (1992) and World Bank (1994b) pointed out that the number of women attending a public outpatient clinic for STDs in Nairobi, Kenya fell by 65 percent following the introduction of user charges, while male attendance decreased by 40 percent. In this regard, World Bank (1993) submitted that except for the rich, out-of-pocket financing couldn't cover expensive care. On the contrary, Lacroix and Alilhonou (1982) study of Benin; Akin et al. (1998) study on Sri Lanka and the World Bank (1987) study on the Philippines showed that price had relatively little impact on health care demand.

Nwabu and Nwangi (1986) asserted that the net welfare effect of improved health services in public clinics depends on how these services are financed. One way to raise revenue to finance these services is to charge for their use. Ching (1995), using a mixed/conditional logit parameterization of the health care demand model to study user charges, demand for children's health care and access across income groups in the Philippines confirmed that the poor are more sensitive to price changes than the rich and this has implications for their willingness and ability to pay. This suggest that user fees are regressive as was asserted

www.ijbed.org A Journal of the Academy of Business and Retail Management (ABRM) 
by Mbanefoh, Soyibo and Anyanwu (1996) in their study of estimating Nigeria's health care demand, though, they did not empirically investigate this issue. Nwabu and Nwangi (1986) simulated the welfare effects of user charges for Kenya. Their study was based on the alternative assumption that user charges is a "pure tax" on government health services and that the revenue generated is used to improve the quality of services in government clinics. They showed that welfare loss from user charges could be reversed by a simultaneous quality improvement, which raised quality in government clinics to the same levels as that of the mission clinics. Revenue, they claimed was enough to enable the achievement of this feat. However, the welfare gains of introducing user charges in all government health facilities are likely to be offset by the attendant equity trade-off (McPake, 1993).

This equity trade-off, which was referred to as distributional effect by some studies like Gertler and Van dar Gaag (1988), is mostly between the poor and the rich. They may both have the willingness to pay but the ability to pay will be lacking in the poor. The equity trade-off was referred to as distributional effect because the imposition of user charges increases the welfare and medical care utilization of individuals in the top half of the income ladder while reducing those of the individual in the bottom half of the income ladder. $\mathrm{Li}$ (1996) collaborated this argument when in a study of the demand for medical care in Bolivia, he cautioned that though uniform user fees can generate substantial revenue, it is likely to reduce the utilization of medical care by the poor. As a result of this, the introduction of price discrimination, referred to as selective pricing by Nwabu and Nwangi (1986), into the user charge proposal was suggested. But its implementation might be difficult because there might be an identification problem. This deals with how you determine that a person is poor (Ching, 1995), given the asymmetry of information that may arise.

A possible solution to this might be to charge people differently based on where they reside (Ching, 1995). In this case, user charges at health facilities in poor villages can be set at levels lower than those of richer villages or even be waived for the poor (Nwabu and Nwangi 1986), especially children (Ching, 1995), who are hurt more by the introduction of user charges than as the poor in general (Gertler and Van dar Gaag, 1990). This means using geographical basis, which is referred to as health zones (Nwabu and Nwangi, 1986) to help identify the poor and consequently improve the attendant user charges. Another solution was to abolish user charges and, in this case, Koch (2012) examined the impact of the abolition of user fees in South Africa, a policy implemented in 1994 for children under the age of six and the elderly, as well as pregnant and nursing mothers, are examined via regression discontinuity. His analysis focuses on provider choice decisions for curative care treatment, and potential externalities that could arise from the policy. His findings indicate that because of abolishing user charges, curative care demand in the public sector increase by about $7 \%$, while those of the private sector decreased by nearly the same amount thereby implying that the abolition led to provider choice substitution. Nimpagaritse and Berton (2011) investigated the sudden removal of user fees in all health centers and hospitals for children under 5 and women giving birth Burundi. Using a descriptive case study approach, they opined that the removal of user fees for certain groups was an equitable and necessary measure in an extremely poor country such as Burundi. However, the suddenness of the decision and the lack of preparation had critical and long-lasting consequences for the entire health system.

Gertler and Van dar Gaag (1988) concluded that if the user charges are below the welfare neutral prices [which increases with income, (Lavy and Germain; 1994)], the policy will be welfare-improving for everyone. The degree to which the price is below the welfare neutral prices determines the improvement in welfare and medical care utilization achieved by the policy.

\section{2: Methodological Issues}

The existence, nature, and determinants of the demand for healthcare have generated a lot of theoretical and methodological debate in the literature. In modeling the demand for health care, various ap- 
proached have been used. These include the Continuous choice model and discrete choice models, (Adhikari, 2011). According to Adhikari, (2011) discrete choice models are typically used to obtain estimates of price elasticities of demand for healthcare while the continuous choice model can analyze the intensity of consumption and can predict the quantities of health care services consumed. Health care expenditure is a measure of the intensity of consumption of the services. According to Train, (2003) and as stated in Adhikari, (2011), logit (binary as well as multinomial) and nested logit are derived under the assumptions that the error terms are independent and identically distributed and extreme value distributed while the probit model (binary as well as multinomial) is derived under the assumption that the unobservable part of utility is normally distributed.

Most studies on the demand for medical care, especially in developing countries, (see Mwabu and Mwangi (1986); Gertler, Locay and Sanderson (1987); Mwabu (1986, 1989); Bitran, R. (1990); Mwabu, Ainsworth and Nyamete (1993); Lavy and Germain, (1994); Akin, Guilkey and Hazel (1993, 1995); Ching, (1995)) assumed that the demand function takes a Multinominal Logit (MNL) form. However, due to the assumption of the Independence of Irrelevant Alternatives (IIA), which possesses a limitation to the MNL, McFadden (1981) introduced a computationally feasible generalization of the MNL, which is the nested Multinominal Logit (NMNL). The Independence of Irrelevant Alternatives (IIA), suggest that stochastic portions of the conditional utility functions are uncorrelated across alternatives and it imposes the restriction that the cross-price elasticities are the same across all alternatives.

The NMNL allows for correlation across subgroups of alternatives and therefore, non-constant cross-price elasticities. The NMNL allows the grouping of more similar alternatives (closer substitutes) so that the cross-price elasticities are more elastic within the groups than across groups. The NMNL also provides a specification test for grouping. The NMNL relates the assumption of the independence of irrelevant alternatives across groups but not within groups. Furthermore, the NMNL is a generalization of the MNL, since the MNL is nested within it. This provides us with a specification test for the MNL. A more general specification, which does not impose any restriction on the cross-price elasticities, would require the estimation of multinomial probit (MNP) models. These models are computationally very difficult when there are more than two choices. The NMNL is a computationally tractable compromise between the very restrictive MNL and the MNP. Moreover, the NMNL provides a specification test to determine whether the data reject the functional form and distributional assumptions. Hensher (1986) shows that full information maximum likelihood estimation of NMNL yields substantial efficiency gains over the more popular two-step procedure. The NMNL provides quantitative relationships between the demand for healthcare and the explanatory variables of the model.

Mcfadden and Train (2000) in their study considered mixed, or random coefficients, multinomial logit (MMNL) models for discrete response, and establishes the following results. Under mild regularity conditions, any discrete choice model derived from random utility maximization has choice probabilities that can be approximated as closely as one pleases by an MMNL model. Practical estimation of a parametric mixing family can be carried out by Maximum Simulated Likelihood Estimation or Method of Simulated Moments, and easily computed instruments are provided that make the latter procedure efficient. Though the MMNL model was introduced by Boyd and Mellman (1980) and Cardell and Dunbar (1980), Mcfadden and Train (2000) also found that an application to a problem of demand for alternative vehicles shows that MMNL provides a flexible and computationally practical approach to discrete response analysis. Farias, Jagabathula, and Shah (2013) did an empirical study with sales data from 14 products types (vehicles) along 16 months from a major US automaker. They calibrated a standard MNL, a mixed MNL and a general RUM using a training data set and then compared the three models using out-of-sample data. The results showed that their non-parametric model improved the prediction accuracy of the other 
two methods by around 20 percent. Muriithi (2013) used a multinomial logit model for his study of Kenya where an individual is assumed to know all the provider-specific attributes and to choose the alternative that maximizes his utility. The observed choice is determined by the differences in utility across alternatives, rather than in levels of utility. This implies that the visit decision involves a comparison of the utility obtained from each option. Gurma and Tesful (2011) examined the effect of access to roads, transport and liquidity on seeking treatment for illness and health care provider choice in urban and rural Ethiopia. They estimated selection probit models for seeking treatment for illness and multinomial logit models for healthcare provider choice controlling for a large set of individual and household characteristics and the got similar results that were consistent with similar studies. They stated that since the magnitudes of the coefficient estimates from multinomial choice model do not tell much by themselves, their discussion thus focused on the average marginal effects of the key variables of interest on provider choice.

\section{1: $\quad$ Methodology}

This study utilized both a Multinomial Logit Model (MNL) and Simulation techniques in investigating whether the imposition user charges in public sector healthcare facilities can lead to large reductions in the usage of the services of the sector or can cause shifts across types of care used.

\subsubsection{The Model}

In this study, a multinomial logit (MNL) model is used because we assumed that the alternative options provide distinct choices, have different attributes and can be mutually exclusive. And, the patient's alternative choices are more than two. This is in line with nearly all studies that concentrate on provider choice, (see Mwabu, et al., 1993; Tembon, 1996; Jianghui, et al., 1997; Dor, et al., 1987; Bedi, et al., 2003).

More specifically, assuming that each $\varepsilon_{i j}$ for all alternatives $j$ is distributed independently and identically in accordance with the extreme value distribution, the demand for provider $j$ (that is, the probability that a patient will choose alternative $j$ ) is given by equation 5 . The demand function for a provider is thus the probability that the utility from that alternative is higher than the utility from any of the other alternatives.

$$
\left(\operatorname{Prob}\left(\text { Option }_{j} \mid H_{i j}\right)=\frac{\exp \left(\beta_{j} H_{i j}\right)}{\sum_{k=0}^{5} \exp \left(\beta_{k} H_{i k}\right)}\right.
$$

The parameter of this model can be estimated using maximum-likelihood methods.

The MNL model requires that the 'independence of irrelevant alternatives' (IIA) assumption be satisfied. This assumption, however, is not realistic in many situations. Train (1990) has indicated that the IIA assumption in the MNL model is not as restrictive as it first seems. An alternative to the MNL model is the nested logit model. However as will be seen in the data section, since all our right-hand side variables are individual characteristics, the nested logit model will essentially produce the same result as the MNL (Econometric Society, 1982). In our data, the unit of observation is the individual. The estimated demand functions were then used to project (using simulation techniques) the effect of increasing user fees on the poor's (low income earners) demand for modern health care.

A limitation of the Multinomial Logit (MNL) model arises from its property of the independence of the relative probability of choice of two alternatives irrespective of the presence or characteristics of other alternatives. This is known as the Independence of Irrelevant Alternatives (llA) and it suggests that the introduction or improvement of any alternative will have the same proportional impact on the probability of each other alternative. Thus, representation of choice-behavior is bound to have biased estimates. 
A way out was our use of the Nested Multinomial Logit (NMNL) which allows interdependence between the pairs of alternatives in a common group (McFadden, 1981) and then predict probability choice in them based on the principle of utility-maximization. Furthermore, the MNL model requires that the independence of irrelevant alternatives' (IIA) assumption be satisfied. This assumption, however, is not realistic in many situations. Train (1990) has indicated that the IIA assumption in the MNL model is not as restrictive as it first seems. An alternative to the MNL model is the nested logit model. Also, in some case some households consulted more than one provider for treatment for the same illness episode and to solve this, the study utilized information based on the first visit to health care provider.

\subsubsection{The Data}

The study utilized mainly primary data. The primary data used were individual and householdbased. Both stratified random and cluster-sampling techniques were utilized. The above was supplemented with a health facility survey. A multi-stage stratified sampling design was adopted for the sampling process. The first stage was the selection of the strata to be sampled. The second stage was the selection of clusters. The third stage was the selection of the households to be interviewed. From each stratum, clusters were drawn and from these clusters, households were randomly chosen. With this method, it was easy to link a community to a particular health facility where a majority of the households living within the cluster went to obtain treatment and this makes it easier to estimate the distance to the health facilities. Moreover, it was easy to collect market prices of consumption goods from the communities.

Facilities were selected for interview on the basis of proximity to a household cluster (this is a geographic area such as a village or neighborhoods of a city). A total of 9,900 households were interviewed (involving 29,700 individuals) using questionnaires. Out of this, 7,920 valid questionnaires (that is, those properly answered) were returned. This represents a response rate of $80 \%$. Accordingly, this total of 7,920 questionnaires was used for the analysis. Households were randomly selected from both rural and urban areas. The questionnaires were administered in such a way that information obtained from the nearest cluster, was linked to a specific household in the cluster. The data were for both outpatients and inpatients in both rural and urban areas.

The survey collected socio-economic information such as household consumption, demographic characteristics, time use, income and consumption, education and health status. The health statistics provided a detailed description of health care and the incidence of morbidity thirty days prior to the survey date including information on the length of illness, choice of treatment, expenditure on consultation and drugs, travel time and cost. Other information sort includes household spending per visit, household total health spending, the composition of household's spending on health services, number of times the selftreatment option was chosen when an illness occurs. The household sample included both individuals who do not report as well as those who reported an illness within four weeks of the survey.

The facility survey collected information about infrastructure, personnel, availability of health services and drugs and fees charged. Other information about the average consultation time, net expenditure per visit, the percentage of people reported ill or injured, government health spending and the cost recovered were also sorted. Providers' quality was measured by the availability of essential drug; the number of medical staff as an indicator of the level of human resources available at the facility which may reflect the sophistication and range of health services provided; the provision of basic adult and child health services measured by the availability of a functioning laboratory, the ability to vaccinate children and the ability to provide prenatal, postnatal and child growth monitoring services (grouped together as 'mother and baby care'); the availability of essential infrastructures like electricity and running water.

The measure of health status prior to treatment was the nature of the illness, which was measured by "illness" dummy variables. This includes what the individual health problem is. Provider dummies 
were also constructed to capture the variations in provider characteristics. Income was measured as total household income in the month prior to the survey while the per capita monthly income was calculated using data for members of the household. The prices for each provider where not directly available were constructed from the money price and/or cost information for each provider given by care recipients. For those who utilized care, the money price and/or cost data were available, but unavailable for those who did not utilize health care. Thus, for each provider, the available (money) cost information was used to estimate cost/price. The non-monetary access utilization price was measured by travel and service time of the providers.

\section{1: $\quad$ Estimation Results}

\subsection{1: $\quad$ Nested Multinomial Logit (NMNL) Results}

The Nested Multinomial Logit (NMNL) model was estimated using full maximum likelihood estimation method. The results are presented in Table 4.1 where our focus will be on our variable of interest which is the price factors. The inclusion of non-linear forms of some variables like age and income is to justify that there could be non-linearity in their relationship with the choice of health care provider. For instance, whether or not there is decreasing health care demand in the very high age groups. The same applies to income.

The price of a consultation is negatively related to the demand for modern health care. This can be attributed to the fact that higher prices (in most cases) discourage demand. Thus, as price increases the probability of seeking modern healthcare reduces. This result agrees slightly with that of Mwabu and Nwangi (1986) that showed, among others, that the demand for health care services in public sector clinic is highly sensitive to changes in relative money prices. The price of a consultation is also significant at $1 \%$ for all the sources of care used namely private and public-sector hospital as well as private and publicsector clinics. This result implies that any increase in the price of consultation (a form of user fees being charged) will have two major effects namely a reduction in the probability of that facility being chosen and secondly, a reduction in the probability of choosing a modern or professional care. This makes the poor and the low-income earners more vulnerable in the demand for professional care as they tend to demand less of this care when the prices get higher.

For the government employee variable, the price of care is positively related to the demand for the public-sector facility but negatively related to the demand for the private facility. It was significant at $1 \%$ for public sector health facilities while for private sector facilities it was not significant. This result could be a manifestation of the policy, which entails government employees, and their families to have access to health care services at public sector health facilities free of charge or at a subsidized price. This implies that with such a government policy, the probability of government employees and their relatives choosing a public-sector health facility becomes higher relative to that of a private facility. With this result, the government employee dummy can be interpreted as a price effect and not as a quality effect. This result was like that of Lavy and Germain (1994). This is also one of the reasons why many low income-earners and the poor consume more of the government healthcare relative to the private care. Most of the low incomeearners and the poor are government employees and they depend more on any subsidy that the government provides for them to ease the cost of care. 
Table 4.1: Multinomial Logit Estimates of Choice of Health Care Provider

\begin{tabular}{|c|c|c|c|c|}
\hline Variable & Public Clinic & Public Hospital & Private Clinic & Private Hospital \\
\hline \multicolumn{5}{|c|}{ Social/Demographic Characteristics } \\
\hline Constant & $-2.34(-6.08) * * *$ & $-1.98(-5.51) * * *$ & $-1.86(-4.46)^{* * *}$ & $-1.77(-5.31)^{* * *}$ \\
\hline Age & $-0.69(-2.61)^{* * *}$ & $0.33(2.12)^{* * *}$ & $-0.55(-2.15)^{* * *}$ & $0.75(2.13)^{* \star *}$ \\
\hline $\mathrm{Age}^{2}$ & $-0.24(-1.62)^{\star *}$ & $0.53(0.86)$ & $-0.44(1.02)^{*}$ & $0.28(1.23)$ \\
\hline $\mathrm{Age}^{3}$ & $-0.31(0.93)$ & $0.45(1.03)^{*}$ & $-0.18(0.32)$ & $0.48(1.56)^{\star *}$ \\
\hline Income & $0.52(0.22)$ & $0.63(0.39)$ & $0.53(0.25)$ & $0.60(0.42)$ \\
\hline Income $^{2}$ & $0.55(0.23)$ & $0.10(0.31)$ & $-0.32(-2.12)^{* * *}$ & $-0.68(-3.34)^{* * *}$ \\
\hline Education & $-1.01(-2.06)^{\star * *}$ & $1.04(2.53)^{* * *}$ & $-0.99(-3.04)^{* * *}$ & $0.05(3.03)^{* * *}$ \\
\hline \multicolumn{5}{|l|}{ Head of Household } \\
\hline *Father & $1.16(2.41)^{* * *}$ & $2.01(2.45)^{* \star *}$ & $1.11(3.60)^{* * *}$ & $-0.02(-0.10)$ \\
\hline${ }^{*}$ Mother & $1.84(2.68)^{* * *}$ & $1.96(2.31)^{* * *}$ & $-0.56(0.31)$ & $-0.71(-0.34)$ \\
\hline *Others & $2.01(4.12)^{* * *}$ & $1.88(2.16)^{* * *}$ & $-0.63(0.44)$ & $-0.42(-0.04)$ \\
\hline \multicolumn{5}{|c|}{ Characteristics of Perceived Illness } \\
\hline $\begin{array}{l}\text { Nature of illness acute } \\
\text { illness (emergencies). }\end{array}$ & $0.67(3.92)^{* * *}$ & $0.43(5.52)^{* * *}$ & $0.81(1.19)^{\star *}$ & $-028(-1.23)^{\star *}$ \\
\hline \multicolumn{5}{|c|}{$2 \quad$ Access for Health care } \\
\hline \multicolumn{5}{|c|}{ *Price factors } \\
\hline Distance (travel time) ${ }^{\mathrm{b}}$ & $-1.25(-3.63)^{\star * *}$ & $-1.25(-3.63)^{\star \star *}$ & $-1.25(-3.63)^{* * *}$ & $-1.25(-3.63)^{* * *}$ \\
\hline Price of Consultation & $-0.33(-3.86)^{\star * *}$ & $-0.89(-3.93)^{* * *}$ & $-1.28(-2.88)^{\star * *}$ & $-2.67(-4.10)^{* * *}$ \\
\hline Government Employee & $0.85(2.41)^{\star \star *}$ & $1.12(3.08)^{\star * *}$ & $-0.00(0.31)$ & $-0.00(0.35)$ \\
\hline \multicolumn{5}{|c|}{$4 \quad{ }^{*}$ Quality of facility } \\
\hline Drugs availability & $1.34(5.81)^{* * *}$ & $1.87(2.05)^{\star * \star}$ & $0.32(6.40)^{* * *}$ & $0.89(5.60)^{* * *}$ \\
\hline Infrastructure & $0.73(2.06)^{* * *}$ & $0.21(2.13)^{\star * *}$ & $0.55(3.25)^{* * *}$ & $0.79(2.16)^{* \star *}$ \\
\hline Personnel & $1.08(2.04)^{* \star *}$ & $0.54(2.05)^{* \star *}$ & $1.02(4.21)^{* * *}$ & $0.47(5.60)^{* * *}$ \\
\hline Services & $0.35(4.34)^{* * *}$ & $0.26(2.89)^{* * *}$ & $0.11(3.11)^{\star * *}$ & $0.61(4.01)^{* * *}$ \\
\hline \multicolumn{5}{|c|}{$\begin{array}{l}\text { Summary Statistics: } \\
\text { Number of Observations: } 7,920 \\
\mathrm{R}^{2} \text { - McFadden: } 0.782 \\
\text {-2 log likelihood: } 1121.691 \\
\text { Chi-Square: } 1060.56 \\
\text { P - Value: } 0.0000\end{array}$} \\
\hline
\end{tabular}

' $\mathrm{t}$ '-statistics are in brackets; ' $\mathrm{b}$ ' - the co-efficients are restarted to be equal across equations

' $c$ '- Price of consultation covers the fee for the service in Nigeria

$\left({ }^{* * *}\right),(* *)$ Significant at $1 \%$ level and $5 \%$ level respectively.

Table 4.1 also shows that distance (travel time) is negatively but significantly different related to the demand for both private and public healthcare facilities. It was significance at $1 \%$. This effect of distance was estimated with the co-efficients been restricted to be equal across equations. The reason for this is to help reduce or minimize the disparity in the opportunity cost of time that will be incurred in traveling to the health facility. This has been argued to be a more important cost incurred in traveling to the health facility (Lavy and Germain, 1994) and it is equal to the time lost during travel (proportional to distance) multiplied by the hourly wage of the individual (which, on average, is proportional to income). If the opportunity cost is large, it discourages households from seeking professional care but if it is relatively less or small, it encourages the demand for professional care by households. This shows that the probability of seeking professional care would significantly increase if health care were more accessible. Also, any 
increase in non-monetary access cost may reduce the demand for professional care. This affects the low income-earners and the poor more as they tend to incur huge opportunity cost of time travelling to the health facility. The reason being that most of them do not have any means of transportation and thus will likely incur huge transportation cost when seeking professional care.

All the quality variables used in the analysis (drug availability, infrastructure, Personnel and Services) were positively related to the demand for professional care. Also, they were all significant at $1 \%$. This implies that households prefer health facilities with adequate and qualified health personnel, up-todate (modern and well-functioning) infrastructure, quality, adequate and diverse health services. The consequence of this is that households will opt for health facilities where drug and diverse services are available, infrastructure is functioning well and there is qualified personnel (doctors and nurses), which they, the households, will prefer to treat them. The implication of this is that households take into account the various dimension of quality of care in making their choices of which health facility to use. Thus, the probability of a household choosing a health facility with better infrastructure as well as where drug and diverse services are available will be higher than where these quality variables are lacking. Also, the estimation result shows that households attach more importance to the probability of their being treated by qualified personnel (doctor or nurse). All these may also attract higher user charges (prices), which will invariably serve as a disincentive for the poor and low-income earners from consuming modern or professional care.

Using the result from table 4.1, a simulation exercise was carried to see the effect of the predicted impact of changes is user charges on the demand for private sector and or public sector health care. The result of this is shown in table 4.2. From the table increasing user charges in public sector health facilities by $25 \%$ led to a decrease of $6.8 \%$ in the usage of public sector health facilities. But it increases the use of private sector health facilities by $1.3 \%$ and that of self-care by $1.1 \%$.

Table 4.2: Increasing User Charges, Predicted Probabilities and Percent Change in Health Care Use

\begin{tabular}{|c|c|c|c|}
\hline & Self-Care & $\begin{array}{l}\text { Public Sector Facil- } \\
\text { ity }\end{array}$ & $\begin{array}{l}\text { Private Sector Fa- } \\
\text { cility }\end{array}$ \\
\hline \multicolumn{4}{|c|}{ Reducing the subsidy on public sector health facilities } \\
\hline Increasing user charges by $25 \%$ & $0.92(1.1)$ & $0.14(-6.8)$ & $0.24(1.3)$ \\
\hline Increasing user charges by $50 \%$ & $0.92(0.4)$ & $0.14(-12.4)$ & $0.24(2.1)$ \\
\hline Increasing User charge by $100 \%$ & $0.92(0.9)$ & $0.13(-22.0)$ & $0.26(3.8)$ \\
\hline \multicolumn{4}{|c|}{$5 \quad$ Increasing user charges in private sector health facilities } \\
\hline Increasing user charged by $25 \%$ & $0.91(1.1)$ & $0.15(6.8)$ & $0.23(-8.5)$ \\
\hline Increasing user charged by $50 \%$ & $0.93(1.7)$ & $0.15(16.1)$ & $0.22(-17.0)$ \\
\hline Increasing user charged by $100 \%$ & $0.75(4.0)$ & $0.05(30.1)$ & $0.03(-32.6)$ \\
\hline \multicolumn{4}{|c|}{$6 \quad$ Increasing user charges in public and private sector health facilities } \\
\hline Increasing user charged by $25 \%$ & $0.93(1.0)$ & $0.14(2.1)$ & $0.24(-7.8)$ \\
\hline Increasing user charged by $50 \%$ & $0.94(1.6)$ & $0.15(3.2)$ & $0.12(-14.8)$ \\
\hline Increasing user charged by $100 \%$ & $0.95(6.0)$ & $0.15(6.0)$ & $0.20(-30.0)$ \\
\hline
\end{tabular}

Note: Percentage changes are in brackets. These are percentage changes relative to a referenced baseline, which was the choice at the mean of the sample characteristics.

When user charges were increased by $50 \%$, it led to a fall of $12.4 \%$ in the use of public sector health facilities while that of the private sector health facilities and self-care increased by $2.1 \%$ and $0.4 \%$ respectively. A $100 \%$ increase in user charges in public sector health facilities increases private sector health care facility usage by $3.8 \%$, while it increased the usage of the self-care option by $0.9 \%$. Thus, by implication, increasing user charges in public sector health facilities will discourage the use of these facili-

www.ijbed.org A Journal of the Academy of Business and Retail Management (ABRM) 
ties and encourage the use of self-care and private sector facilities especially among the low-income earners who utilize these public sector health facilities more.

When the user charges in the private sector health facilities were increased, it also had a negative effect on its usage. For instance when the user charges for the private sector health facilities was increased by $25 \%$, usage of these facilities were reduced by $8.5 \%$ while those of the public sector and self-care increased by $6.8 \%$ and $1.1 \%$ respectively. Also, when the user charges were increased by $50 \%$, the usage rate for public sector facilities rose by $16.1 \%$, self-care rose by $1.7 \%$, while private sector facilities usage fell by $17.0 \%$. The usage of private sector health facilities further fell by $32.6 \%$ when the user charges in these facilities were increased by $100 \%$. In this scenario, the usage rate of public sector facilities rose by $30.1 \%$, while those of self-care rose by $4.0 \%$. The result indicated that the cost of care has influence on the utilization rate of professional health care services. This is because increasing the user charges for private facilities led to a reduction in the usage of the facility and encouraged the usage for alternative care (self-care and public-sector facility).

Furthermore, when the user charges for both private and public-sector facilities were increased, the effect was felt more by the private facilities. For instance, increasing user fees by $25 \%$ in both facilities led to a decrease in the usage rate of private facilities by $7.8 \%$, while that of public sector facilities and selfcare rose respectively by $2.1 \%$ and $1.0 \%$. A $50 \%$ increase in the user fees charged, also led to a reduction in utilization rate of private sector health facilities by $14.8 \%$ while those of the public sector and the self-care option increased by a respective $3.2 \%$ and $1.6 \%$. This demonstrates that when there is an increase in the fees charged in both private sector and public-sector facilities, the use of self-care will be enhanced while the usage of public sector facility will also increase relative to those of the private sector facility. In all, the result shows a significant negative relationship between changes in the cost of treatment and the usage of private sector and public-sector health facilities. It also indicates a significant positive relationship between changes in the cost of treatment and the usage of the self-care option. This can be an explanation why many of the poor and low-income earners utilize the self-care option.

Increasing user fees simultaneously for public and private sector health care gave rise to a relatively large reduction is the demand for private health care and a relative increase in the demand for public sector care. In fact, when all modern health care opportunities become more expensive, consumers (especially low-income earners and the poor) tend to resort more to using public sector health care and the self-care option.

\section{0: $\quad$ Conclusion}

The result showed that the poor (low-income earners) suffers more from the imposition of user charges and further increasing user fees will be regressive and substantially reduce the modern healthcare facility's utilization by the low-income earners, the poor. The poor are more likely to trade-off their utilization of public sector health care services for self-treatment or traditional healers, thus significantly lowering their utilization of any modern medical care. Given that the demand for healthcare is positively related to income, the rich should be encouraged by some deliberate government policies to increase their usage or utilization level of private sector health facilities. Government should introduce price discrimination into the user fee it charges. This will help avoid the adverse distribution effects which user fees have. User charges at clinics in poorer villages and communities can be set at different levels than user charges in rich communities and if the user charge is below the welfare neutral prices the policy will be welfare improving for everyone. More so, the degree to which the price is below the welfare neutral price determines the improvement in welfare and utilization of medical care achieved by the policy. With this type of price discrimination, the clinics in richer villages or areas will be self-financing, while the facilities in poorer villages will require a subsidy. 
Meanwhile, the government needs to establish more operational and equipped public sector healthcare facilities especially in the poor rural areas as this will increase the patronage of professional care in general and public-sector healthcare in specific. This is since the demand for health care services and the willingness to pay has a positive relationship with reduction in the travel time (distance). The government should encourage the private sector health providers to improve their facilities as well as encourage the rich and high-income earners to utilize these private health facilities. This shift will help reduce the pressure on public sector health facilities as well as enable the poor and the more vulnerable groups in the society to be better targeted and provided for by the public health facilities. Drugs, infrastructure, qualified personnel, efficient and diverse services should likewise be provided in public sector healthcare facilities as it will lead to increased usage of public sector health facilities even at a higher cost. This notwithstanding, since the price of a consultation is negatively related to health care utilization, it becomes evident that any increase in these fees will reduce the chance of that facility being chosen as well as reducing the chance of choosing modern health care especially by the poor and low-income earners. Thus, government pricing of these services should be bias towards the poor and low-income earners.

\section{1: $\quad$ Research Limitations and Direction for Further Research}

The sample size was one of the limitations of the study. A bigger sample would have served as a better representative of the country. Another limitation is the small number of health facilities that responded. The number of facilities was not sufficient for the study to adequately estimate the number of health personnel and thus be used in the model. This was also one of the reasons why provider computation of cost of treatment was not used. There were also limitations relating to sampling measurement errors. The measurement error occurs when the observed values of a variable are not a full and accurate representation of the true variable. Likewise, most of the responses were perceived responses as they represent the perceptions by the households. The limitations are not much of a handicap as the results obtained gave much insight into the issue of user changes and healthcare utilization in public sector health facilities in Nigeria. They will also aid policy decisions.

In the future, as improved data exist, and better estimation techniques become available, more services including promotive and preventive care could be analyzed in Nigeria. This kind of research will further help the government to reach members of the community even before the onset of illness. Furthermore, a rigorous analysis of the cost recovery consequences of user charges can also be done. Also, given the regressiveness of user charges, there is the need for a research on the effectiveness of a sliding scale fee or a price discrimination policy in favor of the poor. This will aid the government in the avoidance of unduly restricting access to health care, especially by the poor or low-income earners.

\section{References}

Adhikari, Shiva Raj (2011) "A Methodological Review of Demand Analysis: An Example of Health Care Services". Economic Journal of Development Issues, Vol. 13 \& 14 No. 1-2. Combined Issue

Akin, John S. and Paul Hutchinson (1999), "Health-Care Facility Choice and the Phenomenon of Bypassing", Health Policy and Planning Vol. 14(2): 135-51.

Akin, J., D. Gulkey and E. Hazel (1993), " Multinomial Profit Estimation of Health Care demand: Ogun state, Nigeria", Department of Economics, University of North Carolina, hapel Hill, N.C.

Akin, J., D. Gulkey and E. Hazel (1995), "Quality of service and demand for health care services in Nigeria: A Multinomial Probit Estimation". Social Science and Medicine, 40(11).

Alderman, H. and P.Gertler (1989), "The substitutability of public and private health care for the treatment of children in Pakistan". LSMS working paper, 57, Washington D.C. World Bank.

Alubo, S.O. (1987), 'Power and influence in medical care: an analysis of medical practice in post-colonial Nigeria' Social Science \& Medicine, 24, (5), 453-462. 
Alubo, S. O. (2001), 'The promise and limits of private medicine: health policy dilemmas in Nigeria' Health Policy and Planning, 16 (3), 313-321.

Amaghionyeodiwe, A. Lloyd (2008) "Determinants of the Choice of Health Care Provider in Nigeria". Health Care Management Science, Volume 11, Issue 3, Pp 215-227. September.

Anderson, J.G., (1968), "A behavioral model of families use of health services": Center for health administration studies, University of Chicago.

Appleton, S. (1998), "The Impact of Public Services on Health Care and Illness: A Treatment Effects Model with Sample Selectivity", Journal of African Economies, Vol. 7(1): 1-33.

Ayonrinde, O. L. F. (2002) “User Charges, Quality of Services and Utilization of Modern Health Care Facilities in Oyo State". A Ph.D. thesis submitted to the Department of Economics, University of Ibadan, Ibadan. Nigeria. February.

Bedi, Arjun S, Paul Kimalu, Mwangi Kimenyi, Damiano Manda, Germano Mwabu, Nancy Nafula (2003) “User Charges and Utilization of Health Services in Kenya". Working Paper Series No. 381 Institute of Social Studies, The Hague-The Netherlands.

Bitran, R. (1988) "Health care Demand Studies in Developing Countries" Resources for Child Health, Arlington, V. A.

Bitran, R. (1990) "Household Health care Demand Study in El Salvador, VolumeII: Determinants of Demand for Curative Ambulatory Care". Resources for Child Health Project (REACH), John Snow, Inc., Arlington, February.

Chen, Lincoln C., Emdadul Huq, and Stan DeSouza (1981), "Sex Bias in the Family Allocation of Food and Health Care in Bangladesh", Population and Development Review Vol. 7(1): 55-70.

Ching, P. (1995), "User fees, demand for children's health care and access across income groups: The Philippine case". Social Science and Medicine. Vol. 14, No 1.

Das Gupta, Monica (1987), "Selective Discrimination against Female Children in Rural Punjab, India”, Population and Development Review, Vol. 13(1): 77-100.

De Farranti, D. (1984), "Paying for health Services in Developing Countries: An Overview". World Bank Staff Working. Paper No. 721.

Dor, Avi and Jacques van der Gaag (1987), “The Demand for Medical Care in Developing Countries: Quantity Rationing in Rural Cote d'Ivoire" Living Standards Measurements Study Working Paper No.35, World Bank, Washington D.C.

Dor, A., P. Gertler and J. Van der Gaag (1987), "Non-price Rationing and the Choice of Medical Care Providers in Rural Cote d'Ivoire". Journal of Health Economics. Vol 6. Pp 291 - 304.

Dow, H. Williams (1999) "Flexible Discrete Choice Demand Models Consistent with Utility Maximization: An Application to Health Care Demand". American Journal of Agricultural Economics. 81. August.

Farias, Vivek F. and Jagabathula, Srikanth and Shah, Devavrat, (2017) “Building Optimized and Hyperlocal Product Assortments: A Nonparametric Choice Approach". January. Retrieved from: http://dx.doi.org/10.2139/ssrn.2905381

Farias, Vivek F., Srikanth Jagabathula, and Devavrat Shah. (2013) "A nonparametric approach to modeling choice with limited data". Management Science, 59(2):305-322, 2013.

Federal Office of Statistics (1996) "Socio-Economic Profile of Nigeria", Lagos.

Federal Ministry of Health, (1988). The National Health Policy and Strategy to achieve health for all Nigerians. Lagos, October.

Federal Ministry of Health (2003) Priorities for Action within the Context of Health Sector Reform Agenda, Federal Ministry of Health, Abuja

Federal Ministry of National Planning. 1940-56, 1962-68, 1970-74, 1975-80. 1981-85. The Nigerian National Development Plans. Lagos. Nigeria, Federal Ministry of Health policy and strategy to achieve health for all Nigerians. Lagos, October.

Federal Republic of Nigeria (1993), "First National Rolling Plan: 1990-1992, Lagos.

Federal Republic of Nigeria (1994), "Second National Rolling Plan: 1991-1993". Lagos.

Fosu, Gabriel B. (1994), “Childhood Morbidity and Health Service Utilization: Cross-national comparisons of userrelated factors from DHS data". Social Science and Medicine, Vol. 38 (9).

Garner, P., J. Thomason, and D. Donaldson (1990) "Quality Assessment of Health Facilities in Rural Papua New Guinea." Oxford University Press. 
Gertler, P. and J. Van der Gaag. (1988), "Measuring the willingness to pay for social services in developingcountries". Living Standard Measurement Study (LSMS) working paper, No.45, The World bank, Washington.

Gertler, P and J. van der Gaag (1990), “Willingness to Pay for Medical Care: Evidence from Two Developing Countries", Baltimore, Maryland: Johns Hopkins University Press.

Gertler, P., L. Locay and W. Sanderson (1987), "Are User Fees Regressive? The welfare implications of health care financing proposals in Peru". Journal of Econometrics. Volume 36.

Gurmu, Shiferaw and Solomon Tesfay Tesfu (2011) "Illness and Choice of Treatment in Urban and Rural Ethiopia". Ethiopian Journal of Economics, Volume 20, No. 2. September 16

Heller, P. (1982), "A Model of Demand for Medical and Health Services in Peninsular Malaysia", Social Science and Medicine Vol. 16: 267-284.

Henderson, Gail, et al., (1994), “Equity and Utilization of Health services: Report of an eight province survey in China". Social science and medicine, Vol. 39(5).

Hutchinson (2001), “Combating Illness”, in Ritva Reinikka and Paul Collier (eds.) Uganda's Recover Uganda's Recovery - The Role of Farms, Firms and Government, World Bank: Washington D.C.

Ichoku, H.E. and M. Leibbrandt (2003) “Demand for Health Care Services in Nigeria: A Multivariate Nested Logit Model" African Development Bank. Abidjan.

Jianghui, Li, Cao Suhua, and Henry Lucas, (1997) “Utilization of health services in poor rural China: An analysis using a logistic regression model". IDS Bulletin Vol. 28(1):

Koch, F. Steven (2012) "The Abolition of User Fees and the Demand for Health Care: Re-evaluating the Impact". Economic Research Southern Africa (ERSA) working paper 301. July. Retrieved from: https://econrsa.org/system/files/publications/working_papers/wp301.pdf

Kroeger, A. (1983), “Anthropological and social-medical health care research in developing countries". Social Science and Medicine.

Lacriox, Guy and E. Alihonou (1982), “An Empirical Model of Primary Health Care Demand in Benin”. Working Paper, Laval University.

Lavy, Victor, and Jean-Marc Germain (1994), "Quality and Cost in Health Care Choice in Developing Countries", Living Standards Measurement Study Paper No. 105. World Bank, Washington D.C.

Lavy, Victor and John M. Quigley (1995), “Willingness to Pay for the Quality and Intensity of Medical Care: LowIncome Households in Ghana", Living Standards Measurement Study Paper No. 94. World Bank, Washington D.C.

Li, Masako (1996), “The Demand for Medical Care: Evidence from Urban Areas in Bolivia”, Living Standards Measurement Study Paper No. 123. World Bank, Washington D.C.

Litvack, Jenny I. and Claude Bodart (1993), “User Fees Plus Quality Equals Improved Access to Health Care: Results of a Field Experiment in Cameroon", Social Science and Medicine Vol. 37: 369-383.

Lawson, David (2004) "Determinants of Health Seeking Behaviour in Uganda - Is it Just Income and User Fees That Are Important? Development Economics and Public Policy Working Papers (March). http://ageconsearch.umn.edu/handle/30553

Matji, Madibata et al. (1995) "Do User Fees Reduce the Demand for Health Care: Insights and Limitations of Service Statistics in Lesotho". World Bank Discussion Papers, Africa Technical Department Series 294, Chapter 4. The World Bank, Washington D.C. Pp 67-84.

Mbanefoh, G. F., and A. Soyibo. (1991), "Pathways to Health Delivery in Nigeria". Paper presented to the International Health Policy Programme (IHPP) Nyon, Switzerland. November 18-22.

Mbanefoh, G.F, A. Soyibo and J. C. Anyanwa (1996), "Demand for Health Care in Nigeria: An Econometric Analysis". A Final Research Report Presented at the Writers/Author Workshop Organised by IHPP at the World Bank, March 25 to April 2.

McFadden, D. (1981), "Econometric models of Probabilistic Choice" in C. Manski and D. Mc.Fadden, eds, Structural Analysis of Discrete Data with Econometric Application. Cambridge, M.A., MIT Press

Mcfadden, Daniel and Kenneth Train (2000) “Mixed MNL Models for Discrete Response”. Journal of Applied Econometrics. 15. 
Muriithi, Moses K. (2013) “The Determinants of Health-Seeking Behavior in a Nairobi Slum, Kenya”. European Scientific Journal. March edition vol.9, No.8. Retrieved from:

https://pdfs.semanticscholar.org/236a/51d8b2a8ba5d03213db51c6d576b41745296.pdf

Mwabu, G. and W.H. Mwangi (1986) "Health Care Financing in Kenya: A Simulation of the Welfare Effects of User Fees". Social Science and Medicine. 22, No 7, Pp 763-767.

Mwabu, G. (1986), "Health Care Decisions at the Household level Results of Health Survey in Kenya". Social Science and Medicine, Vol.22, No.3, 313-319.

Mwabu, G. (1989) “Non-Monetary Factors in the Household Choice of Medical Facilities”. Economic Development and Cultural Change. Vol. 37, No 2, Pp 383-392.

Mwabu, G., M. Ainsworth, and A. Nyamete (1993), "Quality of Medical Care and Choice of Medical Treatment in Kenya: An Empirical Analysis". Africa Technical Department, working paper No.9, April, The World Bank.

Mwabu, G., Martha Ainsworth, and Andrew Nyamete, (1996), "The effect of prices, service quality and availability on the demand on the demand for medical care: Insights from Kenya". In R. Paul Shaw and Martha Ainsworth (eds.), Financing health services through user fees and insurance: Case studies from Sub-Saharan Africa. World Bank Discussion Papers 294, Africa Technical Department Series. Washington, D.C., World Bank.

Newbold, K. Bruce, et al, (1995), “Equity in health care: Methodological contribution to the analysis of hospital utilization within Canada". Social Science and Medicine, Vol.40 (9).

Ngugi, R (1999), "Health Seeking Behaviour in The Reform Process for Rural Households: The Case of Mwea Division, Kirinyaga District, Kenya", African Economic Research Consortium Paper No. 95, Nairobi, Kenya.

Nimpagaritse, Manasse and Maria Paola Berton (2011) “The Sudden Removal of User Fees: The Perspective of a Frontline Manager in Burundi". Health Policy and Planning, 26. Pages ii63 - ii71. doi:10.1093/heapol/czr061

Ogunbekun, I., Ogunbekun, A. and Oraton, N. (1999), 'Private healthcare in Nigeria: walking a tightrope' Health Policy and Planning, 14 (2), 174-181.

Peabody, J. W., O. Rahman, K. Fox, and P. Gertler (1993) “Measuring Quality in Primary Health Care Facilities in Jamaica,” RAND, March.

Tembon, Andy C. (1996), "Health care provider choice: The North West Province of Cameroon". International Journal of Health Planning and Management, Vol. 11: 53-57.

Train K. (1990) “Qualitative Choice Analysis”. Cambridge, MA: The MIT Press: Pp 15 - 20.

Train, K. (2003). Discrete choice method with simulation, Cambridge University Press, UK

Vogel, R. (1988) "Cost Recovery in the Health Care Sector: Selected Country Case Studies in Africa". Technical Paper No 82. The World Bank, Washington, D.C.

World Bank (1987), "World Development Report". New York: Oxford University Press.

World Bank (1993), "World Development Report". New York: Oxford University Press.

Yip, Winne, Hong Wang and Yuanli Liu (1998) "Determinants of Patient Choice of medical Provider: A Case Study in Rural China". Health Policy and Planning, Volume 13, Number 3, Pp 311-322.

Yoder, R. A. (1989) “Are People Willing and Able to Pay for Health Services? Social Science and Medicine Vol. 29. 